\title{
Pharmacokinetics of nalbuphine hydrochloride extended release tablets in hemodialysis patients with exploratory effect on pruritus
}

\author{
Amale Hawi ${ }^{1}$, Harry Alcorn $\mathrm{Jr}^{2}$, Jolene Berg ${ }^{2}$, Carey Hines ${ }^{3}$, Howard Hait $^{4}$ and Thomas Sciascia ${ }^{5^{*}}$
}

\begin{abstract}
Background: Uremic pruritus is a common and deleterious condition among hemodialysis (HD) patients. Central gating of $\mu / k$ opiate circuitry plays an important role in mediating and countering pruritogenic sensation. The objective of this study was to assess the safety and pharmacokinetics (PK) of the mixed $\mu$-antagonist/k-agonist nalbuphine, administered orally as nalbuphine $\mathrm{HCl}$ extended release (ER) tablets in $\mathrm{HD}$ patients, and explore its effect on pruritus.
\end{abstract}

Methods: In this open-label multiple escalating dose study, $15 \mathrm{HD}$ patients with pruritus and 9 matched healthy subjects were enrolled. Nalbuphine HCl ER dose was escalated from $30 \mathrm{mg}$ QD to $240 \mathrm{mg}$ BID over 15 days. A full PK profile was obtained under dialysis and non-dialysis conditions as a function of dose. Clearance during dialysis was determined by sampling dialysate and arterial/venous blood during dialysis. Pruritus severity was assessed twice daily using a Visual Analog Scale (VAS). Safety monitoring included extensive monitoring of EKG, blood pressure, and pulse oximetry.

Results: In HD patients, nalbuphine concentration peaked within 4-9 hours and attained steady state within 2-3 days, with no significant accumulation. Mean half-life was 14.2 hours, mean $C_{\max }$ and $A \cup C_{\text {tau }}$ ranged between 13 and $83 \mathrm{ng} / \mathrm{mL}$ and 118 and $761 \mathrm{ng} \cdot \mathrm{h} / \mathrm{mL}$, respectively, with exposure increasing in a nearly dose-proportional fashion. Exposure in HD patients was about 2-fold higher than in healthy subjects. There was no meaningful difference between exposure on dialysis and non-dialysis days with $1 \%$ or less of the dose removed by dialysis. Nalbuphine suppressed itch in a dose-dependent manner, reducing mean VAS score from 4.0 to 1.2 at $180 \mathrm{mg}$ and 0.4 at $240 \mathrm{mg}$.

Conclusions: Nalbuphine HCl ER tablets can be safely administered to HD patients without dose adjustment up to $240 \mathrm{mg} \mathrm{BID}$ and may hold promise in treating uremic pruritus.

Keywords: ESRD, Hemodialysis, Opioid, Pharmacokinetics, Pruritus, Safety, Nalbuphine, Itch

\section{Background}

Uremic pruritus is an itch disorder associated with endstage renal disease (ESRD) that can be severe and debilitating. In its most severe form, uremic pruritus is associated with significant deleterious impairments of patient quality of life, including depression and disruption of sleep $[1,2]$. A $17 \%$ increase in mortality rate $(\mathrm{p}<0.001)$, attributed to sleep disturbances, is associated with moderate to severe pruritus [2,3]. Uremic pruritus is independent of gender,

\footnotetext{
* Correspondence: Thomas.sciascia@trevitherapeutics.com

${ }^{5}$ Trevi Therapeutics, 195 Church Street, 14th Floor, New Haven, CT 06510, USA

Full list of author information is available at the end of the article
}

age, ethnicity, type of dialysis, and the etiology of the underlying renal disease $[3,4]$. Among the factors causing pruritus in ESRD patients are accumulation of uremic toxins, systemic inflammation, cutaneous xerosis, and common comorbidities, e.g. diabetes mellitus and viral hepatitis (4). Currently, there are no approved treatments in the United States or Europe. Uremic pruritus is typically treated with creams, antihistamines, ultraviolet radiation, and the off-label use of various drugs, including opioids, with limited success [4-6]. To date, uremic pruritus remains an unresolved problem with renal transplantation being the only effective treatment $[7,8]$. 
Understanding of the pathogenesis of uremic pruritus has evolved considerably over the past decade as the underlying pathophysiology of pruritus sensation and itch are more rigorously investigated. A mechanistic hypothesis related to peripheral neuropathic changes and central nervous system pathobiology along with evidence for cutaneous microinflammation has recently emerged $[6,9]$. As such, pruritus and pain are believed to share many neurophysiological processes, yet distinct pathways [4]. While central $\mu$-opioid receptor agonism induces itching that can be abolished with $\mu$-antagonists, $\kappa$-opioid receptor agonism inhibits the $\mu$-receptormediated scratching $[10,11]$. Thus the central gating of $\mu / \kappa$ opiate circuitry could be important in countering pruritogenic sensation from a peripheral neurogenic inflammatory initiating event in uremic pruritus [12,13].

In addition to a potential neurophysiological mechanism connected to opioid receptor biology, uremic pruritus has been correlated to an imbalance between the endogenous opiate ligands beta-endorphin ( $\mu$-agonist) and dynorphin A ( $\mathrm{K}$-agonist), resulting in an increased beta-endorphin to dynorphin A serum ratio in uremic patients compared to healthy volunteers [11]. Clinical study data support a role for opioid receptors in mediating itch processing in uremic pruritus: nalfurafine $\mathrm{HCl}$, a pure $\mathrm{\kappa}-$ opioid receptor agonist, has been shown to reduce itch severity and sleep disturbances in uremic pruritus patients $[14,15]$, while naltrexone, a $\mu$-antagonist, has shown some beneficial effect in relieving uremic pruritus-associated itch, although with more limited success [16].

Nalbuphine is a mixed $\mu$-antagonist/ $/$-agonist opioid drug [17], currently marketed as Nalbuphine $\mathrm{HCl}$ for Injection for use in the relief of moderate to severe pain [18]. In addition, nalbuphine has been shown to attenuate morphine-induced pruritus in a number of wellcontrolled, clinical studies [19-23]. More recently, nalbuphine was shown to significantly reduce Substance-P induced itch in a mouse model [24]. In view of its dual agonist/antagonist mechanism of action, nalbuphine may be effective at reducing pruritus by rebalancing opioid $\mu$ and $\kappa$ neuronal activity.

An extended release (ER) nalbuphine solid oral dosage form was developed to facilitate drug administration and patient adherence. Understanding nalbuphine disposition following oral administration in the target $\mathrm{HD}$ patient population is critical as the effects of renal impairment on opioid clearance are variable [25-27]. This study was designed to assess the safety and pharmacokinetics (PK) of nalbuphine administered orally as nalbuphine $\mathrm{HCl}$ ER tablets in renally-impaired HD patients with pruritus following repeated escalating doses over a 6 -fold dose range, and to determine whether nalbuphine is cleared by dialysis. In addition, the effect of nalbuphine on uremic pruritus was explored.

\section{Methods}

This study was sponsored by Trevi Therapeutics and conducted in accordance with the Declaration of Helsinki. All aspects of the study were conducted in accordance with national, state, and local laws and regulations. The study was registered at clinicaltrials.gov (NCT02373215) and the study protocol, all amendments, and informed consent form (ICF) were reviewed and approved by the Investigator, clinic staff, and Institutional Review Board (Western Institutional Review Board, Olympia, WA). All patients provided written, signed informed consent prior to entering the study and before any study-related procedures were performed.

\section{Study drug and administration}

Nalbuphine $\mathrm{HCl}$ ER tablets (30 mg) were provided by Trevi Therapeutics. Unless specified, doses were administered as multiples of $30-\mathrm{mg}$ tablets to achieve the desired dose and with water $(120 \mathrm{ml}) 12$ hours apart with food. All subjects received a renal/diabetic diet. For HD patients on dialysis days, the morning dose was administered no earlier than 6 hours and no later than 4 hours prior to dialysis; the evening dose was administered after the end of dialysis, 12 hours after the morning dose.

\section{Study subjects}

Study subjects were 18-70 years of age. HD patients with Stage 5 chronic end-stage renal disease (ESRD) requiring dialysis reported at least mild intermittent pruritus at Screening (according to the clinical pharmacology unit Checklist of Common Symptoms of Dialysis Patients); had been undergoing dialysis 3x/week for at least 3 months with $\mathrm{Kt} / \mathrm{V}>1.1$ with no significant alteration in regimen within 2 weeks prior to Screening; and had hemoglobin $>9 \mathrm{~g} / \mathrm{dL}$ at Screening. HD patients with alanine and/or aspartate aminotransferase concentration $>2 \mathrm{X}$ the upper limit of normal range (ULN) and serum total bilirubin $>1.8 \mathrm{X}$ ULN at Screening were excluded. Factors that may impact pruritus severity such as predialysis phosphate, urea and CRP levels were not examined in this study.

Healthy subjects were matched with HD patients for body mass index (BMI; within 15\%), age (within 10 years), and gender. For all subjects, exclusion criteria included known hypersensitivity to nalbuphine or opioids; pregnancy or lactation; abnormal laboratory values considered clinically significant by the Investigator; and receipt of barbiturates, amphetamines, or opiates within 7 days prior to check-in.

\section{Study design}

The study was an open-label, single site, multiple escalating dose study comprised of 2 cohorts. Per protocol, Cohort 1 consisted of $14 \mathrm{HD}$ patients divided into four 
groups with 2, 2, 6 and 4 patients in each of Groups 1, 2 , 3, and 4, respectively. Cohort 2 consisted of 8 healthy subjects. Subjects who discontinued study prior to reaching the final dose level (180 $\mathrm{mg}$ or $240 \mathrm{mg}$ ) were replaced. The targeted number of subjects is within the range of sample sizes used in similar Phase 1 clinical studies and is not based on a formal statistical power calculation.

Subjects received a single 30-mg dose on Day 1 . Doses were subsequently escalated to twice daily (BID) $30 \mathrm{mg}$, $60 \mathrm{mg}, 120 \mathrm{mg}, 180 \mathrm{mg}$ over 13 days or to $240 \mathrm{mg}$ BID over 15 days (Cohort 1, Group 4 only). On the last treatment day, subjects received a single 180-mg or 240-mg dose in the morning. Subjects remained at each dose level for 2-3 days (minimum 4 consecutive doses) with dose escalation predicated on tolerability of the prior dose. Subjects remained in the clinic from Day -1 until discharge on Day 14 ( 30 hours after last dose) or Day 17 ( 54 hours after last dose for Cohort 1, Group 4). Subjects returned 5-7 days after discharge for safety followup evaluations. For subjects in Cohort 1, dialysis was conducted at approximately the same time on Days $-1,3$, 5, 7, 10, 12, 14 (and Day 17 for Group 4) over 3-3.5 hours using a high-flux dialyzer with polysulfone membrane (Additional file 1).

Dosing of subjects in Cohort 1 Groups 1-4 was staggered to allow for an interim medical safety review and PK analysis. Since healthy subjects were matched to HD patients, dosing of Cohort 2 was not initiated until Cohort 1 Groups 1-3 were complete and the dosing regimen confirmed. All subjects in Cohort 2 were dosed concurrently. A study schematic is provided in Figure 1.

\section{Pharmacokinetic analyses}

Pharmacokinetic analyses were conducted following US Food and Drug Administration (US FDA) Draft Guidance For Industry On Pharmacokinetics In Patients With
Impaired Renal Function (2010). Analyses included all subjects who received at least 1 dose of study drug and had plasma concentration data above the lower limit of quantitation. Details of sample collection and bioanalytical methods are provided in Additional file 1. Pharmacokinetic parameters were calculated using noncompartmental analysis with WinNonlin Professional v6.2.1 (Pharsight Corporation, Cary, NC). Parameters included area under the plasma concentration-time curve (AUC) from time zero extrapolated to infinity $\left(\mathrm{AUC}_{\mathrm{inf}}\right)$; $\mathrm{AUC}$ from time zero to last measurable concentration $\left(\mathrm{AUC}_{\text {last }}\right)$; $\mathrm{AUC}$ over the 12 hour dosing interval $\left(\mathrm{AUC}_{\text {tau }}\right)$; accumulation ratio (ARAUC $_{\text {tau }}$, based on $\mathrm{AUC}_{\text {tau }}$ Day 4/ $\mathrm{AUC}_{\text {tau }}$ Day 1); area under the arterial plasma concentration versus time from beginning to end of dialysis $\left(\mathrm{AUC}_{\mathrm{d}}\right)$; maximum observed plasma concentration $\left(\mathrm{C}_{\mathrm{max}}\right)$; time of maximum observed plasma concentration $\left(\mathrm{T}_{\max }\right)$; and plasma half-life $\left(\mathrm{T}_{1 / 2}\right)$. Dialysate parameters included amount of drug removed during dialysis for each collection interval $\left(\right.$ Arem $\left._{(\mathrm{t} 1-\mathrm{t} 2)}\right)$; percentage of total amount of drug recovered in the dialysate (\%Arem) calculated as $\operatorname{Arem}_{(0 \text {-end })} /$ dose; and dialysis clearance $\left(\mathrm{CLd}\right.$; Arem $\left._{[0 \mathrm{end}]} / \mathrm{AUC}_{\mathrm{d}}\right)$.

\section{Statistical analyses}

All statistical analyses were performed using SAS v9.1.3 (SAS Institute Inc, Cary, NC). Pharmacokinetic parameters were summarized using descriptive statistics (n, mean, standard deviation [SD], minimum and maximum values, and percentage coefficient of variance $[\mathrm{CV}])$. Descriptive statistics for $\mathrm{T}_{\max }$ were summarized using $\mathrm{n}$, median, minimum, and maximum values. Geometric mean and $\mathrm{CV}$ values were derived for plasma $\mathrm{C}_{\max }$, $\mathrm{AUC}_{\text {last }}, \mathrm{AUC}_{\text {tau }}, \mathrm{AUC}_{\mathrm{d}}, \%$ Arem, and $\mathrm{T}_{1 / 2}$. Attainment of nalbuphine steady-state was assessed based on visual comparison of trough concentrations. The effect of renal impairment on nalbuphine PK was assessed by analysis of variance (ANOVA) on the natural log transformed PK

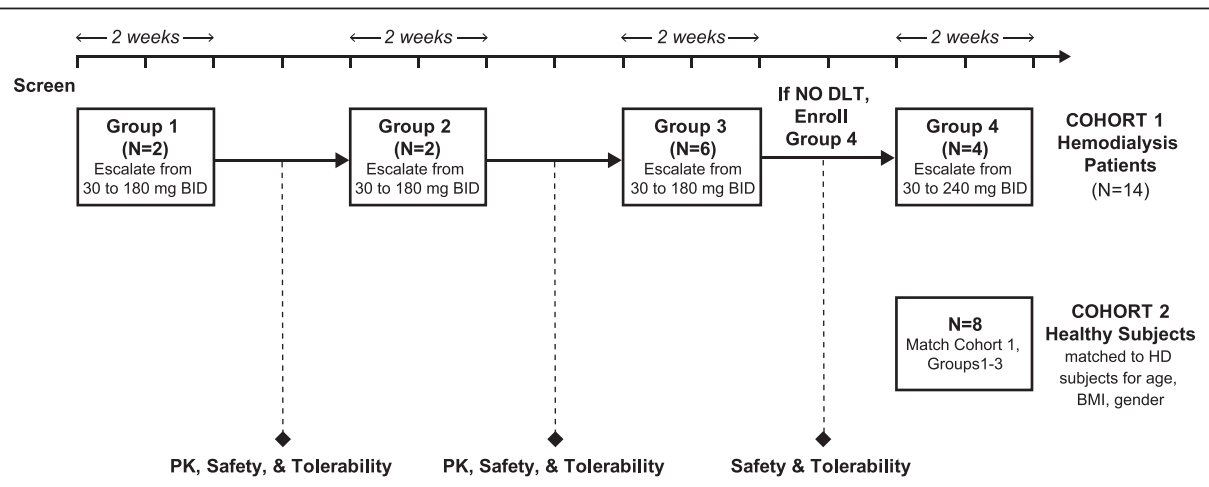

Escalate dose from 30 to $180 \mathrm{mg}$ based on safety. Select dosing regimen and dose range based on PK in

Group 1 \& Group 2. Enroll Group 4 if no dose-limiting toxicity (DLT) noted up to $180 \mathrm{mg}$ BID.

Enroll Cohort 2 (healthy subjects) in parallel with Group 4.

Figure 1 Study schematic. 
parameters (AUC and $\mathrm{C}_{\max }$ ) on dialysis and non-dialysis days using a general linear mixed effect model and measuring the amount of drug removed in the dialysate.

\section{Visual analog scale assessment of itch severity}

Patients self-reported twice a day their worst daytime and nighttime itch intensity using a visual analog scale (VAS) of 0 (none) to $100 \mathrm{~mm}$ (maximal possible intensity) itch score. Patients drew a vertical line between " 0 " and "100" to denote the worst itching. All VAS values were converted to a scale of $0-10$ by dividing the observed value by 10 . The average worst VAS score and change from baseline were calculated for each HD patient at each dose level. Baseline VAS score was defined as the average of the values obtained pre-treatment. Data were summarized using descriptive statistics.

\section{Safety}

Safety assessments included the evaluation of adverse events (AEs), clinical laboratory results (serum chemistry, hematology, urinalysis), vital signs (systolic and diastolic blood pressure, pulse rate, respiratory rate, body temperature) and extensive oxygen saturation $\left(\mathrm{SpO}_{2}\right)$ monitoring, 12-lead electrocardiogram (ECG) measurements, and physical examination findings.

\section{Results}

\section{Patient characteristics}

A total of 24 subjects in 2 cohorts were enrolled: $15 \mathrm{HD}$ patients were enrolled in Cohort 1 (12 males and 3 females), of whom 14 completed the study and 1 discontinued; 9 healthy subjects were enrolled in Cohort 2 (7 males and 2 females), of whom 8 completed the study and 1 discontinued. Healthy subjects were matched to HD patients for gender, BMI and age. Patient characteristics are presented in Additional file 1: Table S1.
Safety

Nalbuphine was well tolerated in all subjects. The most commonly reported treatment emergent AEs (TEAEs) were gastrointestinal and nervous system disorders consistent with the opioid class of drugs. One HD patient discontinued on Day 3 due to a serious $\mathrm{AE}$ (SAE) that was considered unlikely to be study drug related. A second HD patient discontinued due to a nonserious, possibly related, Grade 3 report of vertigo after receiving two 240-mg doses; this subject was not replaced. Among healthy subjects, 1 subject discontinued due to a nonserious combined report of Grade 1 gastroesophageal reflux disease, nausea, and vertigo at the 120-mg dose. No deaths were observed in either cohort and there were no apparent treatment-related trends in clinical laboratory assessments, vital sign and $\mathrm{SpO}_{2}$ measurements, ECG results, or physical examination findings.

\section{Pharmacokinetics}

Mean plasma concentrations for Day 1 and Day 13 as a function of time for HD patients and healthy subjects are shown in Figure 2. In HD patients, nalbuphine plasma profile was characterized by a slow rise in concentration, reaching a peak within 4-9 hours. For many subjects, plasma profiles were characterized by a double peak pattern, which is suggestive of enterohepatic recirculation. Upon repeated dosing, steady state was attained within 2-3 days, with no significant accumulation in exposure beyond that expected for repeat-dosing $\left(\right.$ ARAUC $C_{\text {tau }}=2.7$; Table 1). Mean $C_{\text {max }}$ ranged between 13 and $83 \mathrm{ng} / \mathrm{mL}$ and $\mathrm{AUC}_{\mathrm{tau}}$ between 118 and $761 \mathrm{ng} \cdot \mathrm{h} / \mathrm{mL}$. Mean plasma half life $\left(\mathrm{T}_{1 / 2}\right)$ was 10.5 and 14.2 hours following a single $30-\mathrm{mg}$ and repeat $180-\mathrm{mg}$ BID dose, respectively. Exposure $\left(C_{\max }\right.$ and $\left.A U C_{t a u}\right)$ increased in a nearly dose proportional fashion over the 30-mg to 180-mg BID dose range: 2-, 4-, and 6-fold increases in dose resulted in approximately 2-, 5-, and 6fold increases in mean $\mathrm{C}_{\max }$, and $\mathrm{AUC}_{\text {tau }}$ (Table 2). Note,
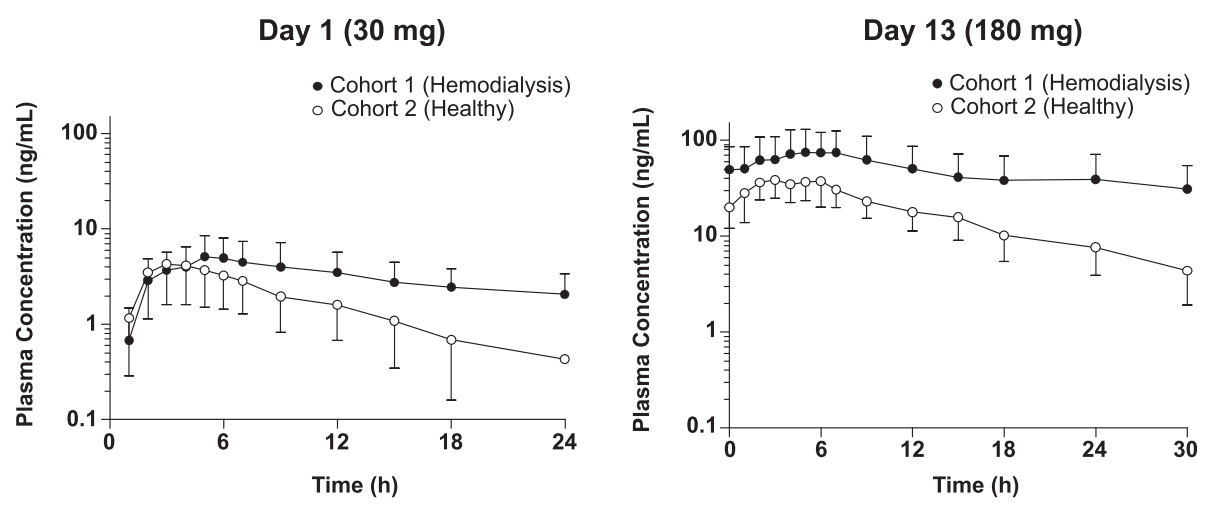

Figure 2 Plasma concentration of nalbuphine in hemodialysis patients and healthy subjects following a single 30-mg dose on day 1 and a single $180-\mathrm{mg}$ dose on day 13 administered orally as nalbuphine $\mathrm{HCl}$ ER tablets. 
Table 1 Mean pharmacokinetic parameters on day 1 and day 13 following multiple nalbuphine oral doses

\begin{tabular}{|c|c|c|c|c|c|}
\hline \multirow[t]{3}{*}{ Parameter } & \multirow[t]{3}{*}{ Statistics } & \multicolumn{2}{|c|}{ Hemodialysis patients } & \multicolumn{2}{|c|}{ Healthy subjects } \\
\hline & & $30 \mathrm{mg}$ QD & $180 \mathrm{mg}$ BID & $30 \mathrm{mg}$ QD & $180 \mathrm{mg}$ BID \\
\hline & & Day 1 & Day 13 & Day 1 & Day 13 \\
\hline \multirow[t]{4}{*}{$\mathrm{AUC}_{\text {inf }}(\mathrm{ng} \cdot \mathrm{h} / \mathrm{mL})$} & $\mathrm{N}$ & 4 & 4 & 7 & 8 \\
\hline & Mean & 142.5 & 2635.38 & 49.53 & 588.40 \\
\hline & SD & 33.28 & 2038.01 & 30.04 & 214.08 \\
\hline & CV\% & 23.4 & 77.3 & 60.7 & 36.4 \\
\hline \multirow[t]{4}{*}{$A U C_{\text {last }}(n g \cdot h / m L)$} & N & 15 & 9 & 9 & 8 \\
\hline & Mean & 73.43 & 1457.74 & 40.55 & 529.85 \\
\hline & SD & 41.81 & 1016.26 & 22.96 & 179.93 \\
\hline & CV\% & 56.9 & 69.7 & 56.6 & 34.0 \\
\hline \multirow[t]{4}{*}{$A \cup C_{\text {tau }}(\mathrm{ng} \cdot \mathrm{h} / \mathrm{mL})$} & N & 15 & 9 & 9 & 8 \\
\hline & Mean & 43.2 & 760.87 & 31.53 & 351.15 \\
\hline & SD & 24.97 & 538.28 & 16.93 & 118.21 \\
\hline & CV & 57.8 & 70.7 & 53.7 & 33.7 \\
\hline ARAUC $_{\text {tau }}$ ratio & Ratio of Mean & 2.7 & NA & 1.6 & NA \\
\hline \multirow[t]{4}{*}{$C_{\max }(n g / m L)$} & $N$ & 15 & 9 & 9 & 8 \\
\hline & Mean & 6.28 & 82.78 & 5.2 & 44.21 \\
\hline & SD & 3.36 & 55.81 & 2.78 & 14.54 \\
\hline & $C V$ & 53.5 & 67.4 & 53.5 & 32.9 \\
\hline \multirow[t]{4}{*}{$\mathbf{T}_{\max }(\mathrm{h})$} & $N$ & 15 & 9 & 9 & 8 \\
\hline & Min & 1.0 & 2.0 & 2.0 & 2.0 \\
\hline & Median & 5.0 & 5.0 & 3.0 & 4.0 \\
\hline & Max & 18 & 7.1 & 5.0 & 6.0 \\
\hline \multirow[t]{4}{*}{$\mathrm{T}_{1 / 2}(\mathrm{~h})$} & $N$ & 4 & 4 & 7 & 8 \\
\hline & Mean & 10.49 & 14.23 & 6.81 & 8.58 \\
\hline & SD & 2.22 & 3.24 & 2.79 & 2.05 \\
\hline & CV & 21.1 & 22.7 & 41.0 & 23.9 \\
\hline
\end{tabular}

Subjects were titrated every 3-4 days from $30 \mathrm{mg}$ QD on Day 1 to $30 \mathrm{mg}$ BID then $60 \mathrm{mg}$ BID, $120 \mathrm{mg}$ BID and finally $180 \mathrm{mg}$ BID over a $14-$ day period. Data shown for Day 1 and Day 13 only.

Abbreviations: $A R A U C_{\text {tau }}$ accumulation ratio (mean $A U C_{\text {tau }}$ Day 4/Mean $A U C_{\text {tau }}$ Day 1), $A U C_{\text {inf }}$ area under plasma concentration-time curve from time zero extrapolated to infinite time, $A \cup C_{\text {last }}$ area under the plasma concentration-time curve from time zero to the last measureable concentration, $A U C_{\text {tau }}$ area under plasma concentration-time curve over dosing interval (0-12 hr), $B I D$ twice daily, $C_{\max }$ maximum observed plasma concentration, $C V$ coefficient of variation, $E R$ extended release, $h$ hour, $M a x$ maximum, Min minimum, $n$ number of subjects, $N A$ not applicable, $Q D$ once daily, $T_{\max }$ time of maximum observed plasma concentration, $T_{1 / 2}$ plasma half life.

data from the 240-mg BID dose are shown for completeness but were not included in the analysis due to the small sample size.

In healthy subjects, mean exposure ranged from 5.2 to $44.2 \mathrm{ng} / \mathrm{mL}$ for $\mathrm{C}_{\max }$ and from 31.5 to $351.2 \mathrm{ng} \cdot \mathrm{hr} /$ $\mathrm{mL}$ for $\mathrm{AUC}_{\text {tau }}$ over the 30 -mg to 180 -mg dose range, with median $\mathrm{T}_{\max }$ between 2 and 5 hours. As with HD patients, steady state appeared to be attained within 23 days of dosing, with a modest accumulation in exposure $\left(\right.$ ARAUC $\left._{\mathrm{tau}}=1.6\right)$. Mean $\mathrm{T}_{1 / 2}$ was 6.8 and 8.6 hours following a single $30-\mathrm{mg}$ and repeat 180-mg BID dose, respectively (Table 1, Additional file 1: Table S2). Exposure in HD patients was significantly higher by $65 \%$
$\left(\mathrm{C}_{\text {max }}\right)$ and $83 \%\left(\mathrm{AUC}_{\text {tau }}\right)$ compared to healthy subjects, while $\mathrm{T}_{1 / 2}$ was 1.6 -fold longer than in healthy subjects (Additional file 1: Table S3). Overall intersubject variability was high, particularly in HD patients (CV range $54 \%-71 \%$ for $C_{\max }$ and $A U C_{\text {tau }}$ ) compared to healthy subjects (CV range 33\%-56\%). An overlay of nalbuphine plasma concentration profiles as a function of time, dose, and study day for Cohorts 1 and 2 is shown in Figure 3.

\section{Effect of dialysis on nalbuphine pharmacokinetics}

Mean PK parameters for HD patients on dialysis days and non-dialysis days as a function of dose are compared 
Table 2 Mean pharmacokinetic parameters following multiple escalating oral nalbuphine doses in hemodialysis patients

\begin{tabular}{|c|c|c|c|c|c|c|c|c|c|c|c|}
\hline \multirow[t]{3}{*}{ Parameter } & \multirow[t]{3}{*}{ Statistics } & \multicolumn{5}{|c|}{ Non-dialysis days } & \multicolumn{5}{|c|}{ Dialysis days } \\
\hline & & $30 \mathrm{mg}$ BID & 60 mg BID & $120 \mathrm{mg} \mathrm{BID}$ & $180 \mathrm{mg} \mathrm{BID}$ & $240 \mathrm{mg} \mathrm{BID}$ & $30 \mathrm{mg}$ BID & $60 \mathrm{mg}$ BID & $120 \mathrm{mg} \mathrm{BID}$ & $180 \mathrm{mg} \mathrm{BID}$ & $240 \mathrm{mg}$ BID \\
\hline & & Day 4 & Day 6 & Day 9 & Day 13 & Day 15 & Day 3 & Day 7 & Day 10 & Day 12 & Day 14 \\
\hline \multirow[t]{4}{*}{$\mathrm{AUC}_{\mathrm{tau}}(\mathrm{ng} \cdot \mathrm{h} / \mathrm{mL})$} & $n$ & 14 & 10 & 10 & 9 & 3 & 11 & 10 & 10 & 13 & 3 \\
\hline & Mean & 117.97 & 221.68 & 621.79 & 760.87 & 769.99 & 118.56 & 255.54 & 582.15 & 646.06 & 539.72 \\
\hline & SD & 76.41 & 145.04 & 415.94 & 538.28 & 509.88 & 74.93 & 157.81 & 374.09 & 433.26 & 476.19 \\
\hline & CV & 64.8 & 65.4 & 66.9 & 70.7 & 66.2 & 63.2 & 61.8 & 64.3 & 67.1 & 88.2 \\
\hline \multirow[t]{4}{*}{$C_{\max }(\mathrm{ng} / \mathrm{mL})$} & $n$ & 14 & 10 & 10 & 9 & 3 & 11 & 10 & 10 & 13 & 4 \\
\hline & Mean & 13.44 & 24.78 & 70.33 & 82.78 & 80.47 & 12.84 & 27.04 & 62.51 & 69.12 & 63.45 \\
\hline & SD & 8.31 & 17.38 & 48.81 & 55.81 & 51.76 & 7.71 & 15.74 & 40.11 & 47.20 & 40.10 \\
\hline & CV & 61.8 & 70.1 & 69.4 & 67.4 & 64.3 & 60.1 & 58.2 & 64.2 & 68.3 & 63.2 \\
\hline \multirow[t]{4}{*}{$\mathbf{T}_{\max }(h)$} & $n$ & 14 & 10 & 10 & 9 & 3 & 11 & 10 & 10 & 13 & 4 \\
\hline & Min & 0 & 0 & 3.0 & 2.0 & 3.1 & 2.0 & 0 & 0 & 0 & 0 \\
\hline & Median & 4.0 & 5.0 & 6.0 & 5.0 & 9.0 & 4.0 & 4.0 & 3.5 & 3.0 & 2.0 \\
\hline & Max & 9.0 & 9.0 & 9.0 & 7.1 & 12.0 & 11.9 & 11.9 & 4.0 & 11.9 & 4.0 \\
\hline \multirow[t]{4}{*}{$\mathrm{AUC}_{\mathrm{d}}(\mathrm{ng} \cdot \mathrm{h} / \mathrm{mL})$} & $n$ & & & & & & 11 & 10 & 10 & 9 & \\
\hline & Mean & NA & NA & NA & NA & NA & 40.57 & 86.87 & 194.95 & 280.33 & NA \\
\hline & SD & & & & & & 28.14 & 55.63 & 136.98 & 217.42 & \\
\hline & CV\% & & & & & & 69.4 & 64.0 & 70.3 & 77.6 & \\
\hline \multirow[t]{4}{*}{ \%Arem } & $n$ & & & & & & 11 & 10 & 10 & 9 & \\
\hline & Mean & NA & NA & NA & NA & NA & 0.95 & 1.07 & 1.24 & 1.11 & NA \\
\hline & SD & & & & & & 0.69 & 0.74 & 0.91 & 0.85 & \\
\hline & CV\% & & & & & & 73.0 & 69.2 & 73.1 & 76.0 & \\
\hline \multirow[t]{4}{*}{$\mathrm{CL}_{\mathrm{d}}^{\mathrm{a}}(\mathrm{L} / \mathrm{h})$} & $n$ & & & & & & 11 & 10 & 10 & 9 & \\
\hline & Mean & NA & NA & NA & NA & NA & 6.98 & 7.33 & 7.60 & 7.32 & NA \\
\hline & SD & & & & & & 1.40 & 1.16 & 1.30 & 1.04 & \\
\hline & CV\% & & & & & & 20.1 & 15.8 & 17.1 & 14.2 & \\
\hline
\end{tabular}

Abbreviations: \%Arem percentage of total amount of drug removed by hemodialysis, $A U C_{d}$ area under arterial plasma concentration-time curve from beginning to end of dialysis, $A U C_{\text {tau }}$ area under plasma concentration-time curve over $12 \mathrm{~h}, B I D$ twice daily, $C L_{d}$ dialysis clearance, $C_{\max }$ maximum observed plasma concentration, $C V$ coefficient of variation, $E R$ extended release, $h$ hour, $n$ number of subjects, NA not applicable, $Q D$ once daily, $T_{\max }$ time of maximum observed plasma concentration. 


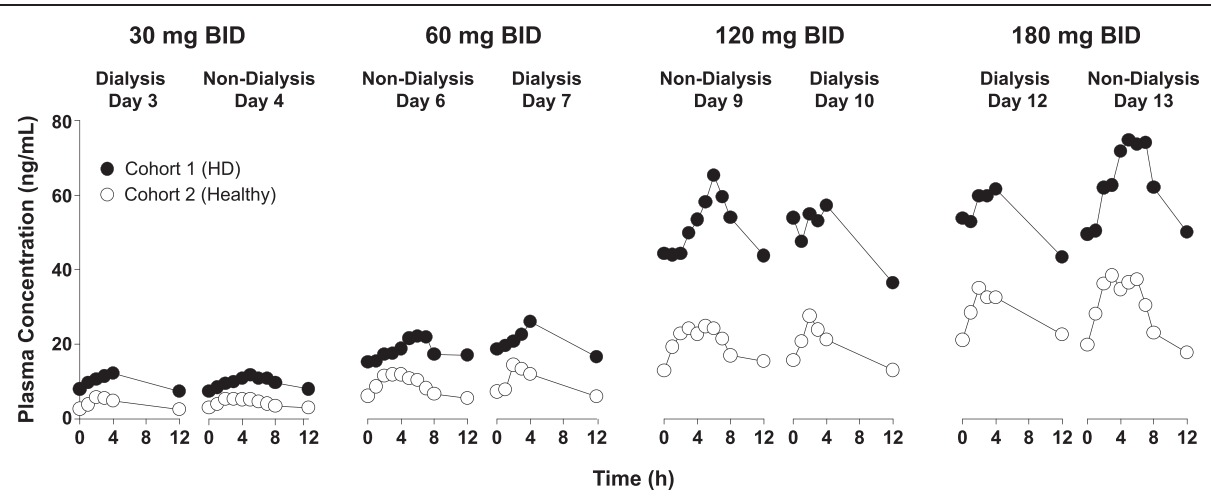

Figure 3 Plasma concentration of nalbuphine, administered orally as nalbuphine HCl ER tablets, as a function of day and dose.

in Table 2. Summary statistics for nalbuphine PK parameters are provided in Table 3. Nalbuphine exposure in HD patients on dialysis days and non-dialysis days was comparable. The geometric mean ratio for dialysis/nondialysis days (90\% confidence interval [CI]) was 98.90 (89.73-109.01) for $\mathrm{C}_{\max }$ for all doses; and 91.85 (81.02104.12), 94.51 (83.46-107.03) and 94.64 (82.95-107.99) for $\mathrm{AUC}_{\text {tau }}$ at the 30, 120 and 180-mg dose levels, respectively. Despite the small number of subjects, the 90\% $\mathrm{CI}$ for $\mathrm{C}_{\max }$ and $\mathrm{AUC}_{0 \text {-last }}$ were fully contained within the $80 \%$ to $125 \%$ confidence limits except at the 60-mg dose, where the upper $90 \% \mathrm{CI}$ for $\mathrm{AUC}_{\text {tau }}$ was outside the upper limit. Regardless, the observed difference of $18 \%$ is small and was not considered clinically relevant in view of the rather high intersubject variability.

Analysis of nalbuphine concentration in dialysate indicated that $0.95 \%-1.24 \%$ of the dose was removed during a standard high-flux 3-4 hour hemodialysis session over the dosing range (\%Arem; Table 2). Clearance during dialysis $\left(\mathrm{CL}_{\mathrm{d}}\right)$, calculated based on arterial blood sampling from the dialyzer port during dialysis, was 77.6 L/kg (or $116-127 \mathrm{~mL} / \mathrm{min}$ ) and approximated the creatinine clearance in subjects with normal kidney function (>90 $\mathrm{mL} / \mathrm{min})$.

\section{VAS assessment of itch severity}

The impact of nalbuphine $\mathrm{HCl}$ ER tablets on uremic pruritus was explored in HD patients who self-reported itch intensity using a VAS score. Nalbuphine suppressed itch in a dose-dependent manner in 12/14 patients, reducing itch from a mean VAS score of 4.0 (range, 1.3-6.6) to 1.2 and 0.4 at $180 \mathrm{mg}$ and $240 \mathrm{mg}$, respectively (Table 4, Figure 4A). Itch intensity in HD patients is reported to fluctuate and appears to be cyclical in some patients [1]. However, patients with a baseline VAS above $4(40 \mathrm{~mm})$ are reported to have a more persistent itch (daily or nearly daily) and changes in VAS of at least $20 \%$ in either direction are considered indicative of a change in patient-rated pruritus severity [1]. Of the 14 patients assessed in this study, 8 had VAS score $\geq 4.0$ (mean, 5.1; range, 4.2-6.6). Subgroup analysis of these patients showed a more pronounced change compared to all patients treated, with a mean change from baseline of $-1.2,-2.2,-3.4,-3.6$ and -4.9 at the 30-, 60-, 120-, 180- and 240-mg BID doses, respectively, with the largest incremental changes occurring between $60 \mathrm{mg}$ and $120 \mathrm{mg}$ BID (Table 4, Figure 4B).

\section{Discussion}

Pharmacokinetics of nalbuphine following oral administration of nalbuphine $\mathrm{HCl}$ ER tablets up to 15 days were

Table 3 Statistical analysis of the effects of hemodialysis on the pharmacokinetics of nalbuphine

\begin{tabular}{|c|c|c|c|c|c|c|}
\hline \multirow[t]{2}{*}{ Parameter } & \multirow[t]{2}{*}{ Dose (mg) } & \multirow[t]{2}{*}{$\mathbf{N}^{\mathrm{a}}$} & \multicolumn{2}{|l|}{ Geometric means } & \multicolumn{2}{|l|}{ Statistics } \\
\hline & & & On dialysis (test, T) & Non-dialysis (reference, R) & GMR (T/R) & $90 \%$ Confidence limit \\
\hline \multirow[t]{4}{*}{$\mathrm{AUC}_{\text {tau }}(\mathrm{ng} \cdot \mathrm{h} / \mathrm{mL})$} & 30 & $11 / 14$ & 86.46 & 94.14 & 91.85 & $81.02,104.12$ \\
\hline & 60 & $10 / 10$ & 188.59 & 159.84 & 117.99 & $103.56,134.43$ \\
\hline & 120 & $10 / 10$ & 418.26 & 442.56 & 94.51 & $83.46,107.03$ \\
\hline & 180 & $13 / 9$ & 567.05 & 599.15 & 94.64 & $82.95,107.99$ \\
\hline$C_{\max }(n g / m L)$ & All doses & $15 / 14$ & 31.04 & 31.39 & 98.90 & $89.73,109.01$ \\
\hline
\end{tabular}

${ }^{a}$ Number of patients on dialysis/non-dialysis days.

Abbreviations: $A \cup C_{\text {tau }}$ area under the plasma concentration-time curve over the dosing interval, $C l$ confidence interval, $C_{\text {max }}$ maximum observed plasma concentration, $h$ hour, GMR geometric mean ratio. 
Table 4 Mean VAS score as a function of nalbuphine oral dose in hemodialysis patients

\begin{tabular}{|c|c|c|c|c|c|}
\hline \multirow[t]{2}{*}{ Dose } & \multirow[t]{2}{*}{ Statistics } & \multicolumn{2}{|l|}{ VAS score } & \multicolumn{2}{|c|}{ Change from baseline } \\
\hline & & All patients & Patients with VAS $\geq 4.0$ & All patients & Patients with VAS $\geq 4.0$ \\
\hline \multirow[t]{4}{*}{ Baseline } & $\mathrm{N}$ & 14 & 8 & - & - \\
\hline & Mean (SD) & $4.0(1.5)$ & $5.1(0.8)$ & & \\
\hline & Median & 4.4 & 4.9 & & \\
\hline & Min, Max & $1.3,6.6$ & $4.2,6.6$ & & \\
\hline \multirow[t]{4}{*}{30 mg BID } & $\mathrm{N}$ & 14 & 8 & 14 & 8 \\
\hline & Mean (SD) & $3.1(1.9)$ & $3.9(1.9)$ & $-0.9(1.3)$ & $-1.2(1.5)$ \\
\hline & Median & 2.8 & 3.2 & -0.5 & -1.7 \\
\hline & Min, Max & $0.4,6.7$ & $1.4,6.7$ & $-3.2,0.8$ & $-3.2,0.8$ \\
\hline \multirow[t]{4}{*}{$60 \mathrm{mg}$ BID } & $\mathrm{N}$ & 14 & 8 & 14 & 8 \\
\hline & Mean (SD) & $2.3(2.0)$ & $2.9(2.2)$ & $-1.7(1.8)$ & $-2.2(1.8)$ \\
\hline & Median & 1.9 & 2.8 & -1.5 & -1.8 \\
\hline & Min, Max & $0.1,6.2$ & $0.1,6.2$ & $-4.3,1.2$ & $-4.3,0.8$ \\
\hline \multirow[t]{4}{*}{$120 \mathrm{mg}$ BID } & $\mathrm{N}$ & 14 & 8 & 14 & 8 \\
\hline & Mean (SD) & $1.6(1.8)$ & $1.7(2.1)$ & $-2.4(1.9)$ & $-3.4(1.9)$ \\
\hline & Median & 0.8 & 0.9 & -2.6 & -4.0 \\
\hline & Min, Max & 0.0 .6 .1 & $0.0,6.1$ & $-5.5,0.9$ & $-5.5,0.7$ \\
\hline \multirow[t]{4}{*}{$180 \mathrm{mg}$ BID } & $\mathrm{N}$ & 13 & 7 & 13 & 7 \\
\hline & Mean (SD) & $1.2(1.6)$ & $1.6(2.0)$ & $-2.8(1.7)$ & $-3.6(1.8)$ \\
\hline & Median & 0.8 & 0.8 & -2.6 & -3.9 \\
\hline & Min, Max & $0.0,5.8$ & $0.1,5.8$ & $-5.1,0.4$ & $-5.1,0.4$ \\
\hline \multirow[t]{4}{*}{$240 \mathrm{mg}$ BID } & $\mathrm{N}$ & 4 & 2 & 4 & 2 \\
\hline & Mean (SD) & $0.4(0.5)$ & $0.7(0.6)$ & $-3.1(2.1)$ & $-4.9(0.8)$ \\
\hline & Median & 0.3 & 0.7 & -2.8 & -4.9 \\
\hline & Min, Max & $0.0,1.2$ & $0.3,1.2$ & $-5.5,-1.3$ & $-5.5,-4.3$ \\
\hline
\end{tabular}

Abbreviations: BID twice daily, ER extended release, $S D$ standard deviation, VAS visual analog scale.

assessed in HD patients with pruritus compared to matched healthy control subjects. A dose-escalation study design was selected to mimic nalbuphine use in uremic pruritus patients in subsequent clinical efficacy studies where patients would start at a low dose to minimize common opioid AEs such as nausea and vomiting and allow development of some tolerance to these particular AEs. Ultimately, nalbuphine would be titrated to effect, as is standard in opioid treatment, and a washout period between doses would counter the intent of titration, hence the continuous escalation from $30 \mathrm{mg}$ to $240 \mathrm{mg}$ in this study. Nalbuphine is a low molecular weight, water soluble molecule, with low protein binding $(\sim 50 \%)$ and a large volume of distribution (315.5 L) [28,29]. Nalbuphine is a high extraction (perfusion-limited) drug [29], predominantly hepatically cleared in the feces $[30,31]$. In HD patients, changes in hepatic blood flow as well as diffusion of the drug through the dialysis membrane have the potential to affect nalbuphine exposure, although the large volume of distribution is expected to offset the dialysis effect. In this study we show that nalbuphine exposure in HD patients on non-dialysis and dialysis days was comparable over a 6 -fold dose range with only $1 \%$ of the dose being removed by dialysis. There was no significant drug accumulation, beyond that expected for repeat dosing. Collectively, these findings indicate that no dose adjustment around dialysis treatment is needed.

Following repeat dosing, nalbuphine exposure increased in a nearly dose-proportional fashion, reaching steady state within 2-3 days at all dose levels suggesting that additional accumulation due to more prolonged exposure is unlikely. Exposure was significantly higher in HD patients than healthy subjects $(83 \%$ and 65\% increase in $\mathrm{AUC}_{\text {tau }}$ and $\mathrm{C}_{\max }$ ), most likely due to the longer half-life in $\mathrm{HD}$ patients. 


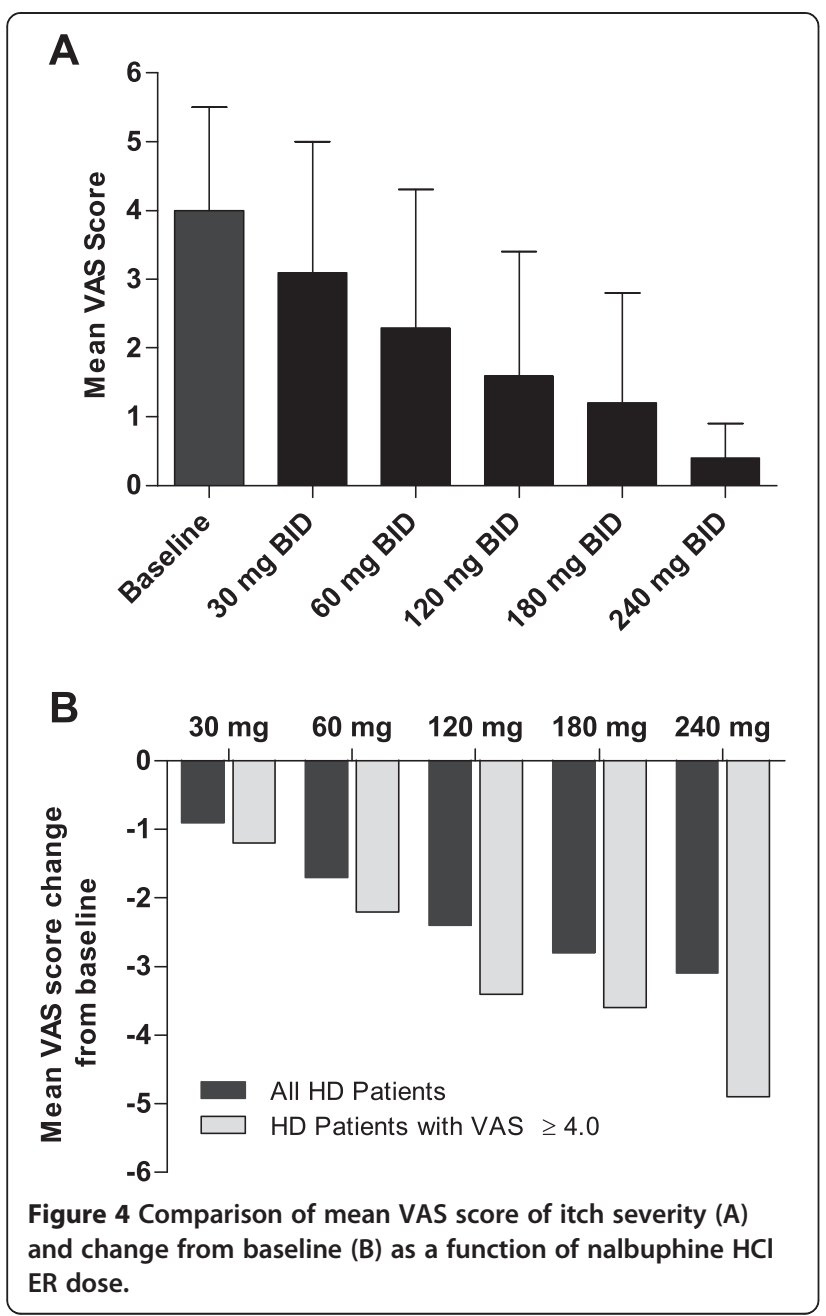

Nalbuphine is metabolized and cleared by the liver thus both liver function and genetic differences in drug metabolizing enzymes and transporters among race groups could potentially result in variability in pharmacokinetics. For the marketed Nalbuphine $\mathrm{HCl}$ for Injection, dose reduction is recommended in patients with hepatic dysfunction [18] since higher exposures are expected. In this study, only subjects with normal to mild impaired liver function were included as the effect of significant co-existing liver disease on nalbuphine safety and exposure in HD patients is not yet understood. It is also worth noting that there were more blacks or African Americans enrolled in the HD group (73\%) compared to the healthy subjects (44\%). Whether race played a role in the pharmacokinetic differentiation between HD patients and healthy subjects cannot be gauged from this study due to the small number of subjects. However, it does underscore the need for evaluation of the role of polymorphisms in metabolic pathways on nalbuphine exposure in future clinical studies.

Assessments of AEs, clinical laboratory results, vital signs, oxygen saturation, and physical examination findings demonstrated that nalbuphine $\mathrm{HCl}$ ER oral tablets were safe and well-tolerated up to the 240-mg BID dose tested in HD patients. Moreover, while this study was not specifically designed to assess effects on uremic pruritus, discernible reductions in VAS measures of itch severity did appear to be a function of increasing nalbuphine dose in HD patients despite the limited sample size.

\section{Conclusions}

In summary, nalbuphine administered as oral nalbuphine $\mathrm{HCl}$ ER tablets was safe and well-tolerated in HD patients. Nalbuphine is not extracted by dialysis. Exploratory investigations suggest that nalbuphine $\mathrm{HCl}$ ER tablets may be effective in reducing pruritus in HD patients, with particular benefit at doses of $60 \mathrm{mg}$ BID or higher. Well-controlled clinical efficacy studies will be conducted to establish the longitudinal effect of treatment with nalbuphine $\mathrm{HCl}$ ER tablets on uremic pruritus and assess its long term safety.

\section{Additional files}

Additional file 1: Table S1. Patient Demographics and Baseline Characteristics. Table S2. Mean Pharmacokinetic Parameters Following Multiple Escalating Oral Doses of Nalbuphine $\mathrm{HCl}$ ER Tablets in Cohort 2 Healthy Subjects on Non-Dialysis and Dialysis Days. Table S3. Statistical Analysis of the Pharmacokinetics of Nalbuphine in Hemodialysis Patients Versus Healthy Subjects.

\section{Competing interests}

$\mathrm{AH}$ is a consultant for Trevi Therapeutics and holds stock in Trevi Therapeutics; HA is an employee of DaVita Clinical Research; JB is an employee of DaVita Clinical Research; $\mathrm{CH}$ is an employee of PPD; $\mathrm{HH}$ is a paid statistical consultant for Trevi Therapeutics; TS is an employee of Trevi Therapeutics and holds stock in Trevi Therapeutics.

This study was sponsored by Trevi Therapeutics.

\section{Authors' contributions}

Study Design and Data Interpretation: AH, HA, JB, TS. Statistical Analysis: AH, CH, $\mathrm{HH}$. Manuscript Draft: $\mathrm{AH}$; all authors read and approved the final manuscript.

\section{Acknowledgements}

The authors acknowledge Tandem Labs-RTP, NC, for performing the bioanalytical assays and Abigail Hunt, PhD, of DaVita Clinical Research for editorial assistance in preparing this manuscript. Funding for manuscript preparation support was provided by Trevi Therapeutics.

Data from this manuscript were presented in poster form at the Society for Investigative Dermatology Annual Meeting held in Albuquerque, NM, May 7-10, 2014.

\section{Author details}

${ }^{1}$ A Hawi Consulting, Ridgefield, CT, USA. ${ }^{2}$ DaVita Clinical Research, Minneapolis, MN, USA. ${ }^{3}$ PPD, Richmond, VA, USA. ${ }^{4}$ Edenridge Associates LLC, Wilmington, DE, USA. ${ }^{5}$ Trevi Therapeutics, 195 Church Street, 14th Floor, New Haven, CT 06510, USA. 
Received: 15 August 2014 Accepted: 31 March 2015

Published online: 08 April 2015

\section{References}

1. Mathur VS, Lindberg J, Germain M, Block G, Tumlin J, Smith M, et al. A longitudinal study of uremic pruritus in hemodialysis patients. Clin J Am Soc Nephrol. 2010;5(8):1410-9.

2. Pisoni RL, Wikstrom B, Elder SJ, Akizawa T, Asano Y, Keen ML, et al. Pruritus in haemodialysis patients: International results from the Dialysis Outcomes and Practice Patterns Study (DOPPS). Nephrol Dial Transplant. 2006;21(12):3495-505.

3. Narita I, Alchi B, Omori K, Sato F, Ajiro J, Saga D, et al. Etiology and prognostic significance of severe uremic pruritus in chronic hemodialysis patients. Kidney Int. 2006;69(9):1626-32.

4. Manenti L, Tansinda P, Vaglio A. Uraemic pruritus: clinical characteristics, pathophysiology and treatment. Drugs. 2009;69(3):251-63.

5. Mettang $M$, Weisshaar E. Pruritus: control of itch in patients undergoing dialysis. Skin Therapy Lett. 2010;15(2):1-5.

6. Mettang T, Kremer AE: Uremic pruritus. Kidney Int 2014. Jan 8. doi:10.1038/ki.2013.454.

7. Legroux-Crespel E, Cledes J, Misery L. A comparative study on the effects of naltrexone and loratadine on uremic pruritus. Dermatology. 2004;208(4):326-30.

8. Patel TS, Freedman BI, Yosipovitch $\mathrm{G}$. An update on pruritus associated with CKD. Am J Kidney Dis. 2007;50(1):11-20.

9. Paus R, Schmelz M, Biro T, Steinhoff M. Frontiers in pruritus research: scratching the brain for more effective itch therapy. J Clin Invest. 2006:116(5):1174-86.

10. Umeuchi H, Togashi Y, Honda T, Nakao K, Okano K, Tanaka T, et al. Involvement of central mu-opioid system in the scratching behavior in mice, and the suppression of it by the activation of kappa-opioid system. Eur J Pharmacol. 2003;477(1):29-35.

11. Kumagai H, Saruta T, Matsukawa S, Utsumi J. Prospects for a novel kappa-opioid receptor agonist, TRK-820, in uremic pruritus. In: Itch, Basic Mechanisms and Therapy. New York: Marcel Dekker Inc; 2004.

12. Pan ZZ. mu-Opposing actions of the kappa-opioid receptor. Trends Pharmacol Sci. 1998;19(3):94-8.

13. Schmelz M. Itch and pain. Dermatol Ther. 2005;18(4):304-7.

14. Kumagai H, Ebata T, Takamori K, Muramatsu T, Nakamoto H, Suzuki H. Effect of a novel kappa-receptor agonist, nalfurafine hydrochloride, on severe itch in 337 haemodialysis patients: a Phase III, randomized, double-blind, placebo-controlled study. Nephrol Dial Transplant. 2010;25(4):1251-7.

15. Wikstrom B, Gellert R, Ladefoged SD, Danda Y, Akai M, Ide K, et al. Kappaopioid system in uremic pruritus: multicenter, randomized, double-blind, placebo-controlled clinical studies. J Am Soc Nephrol. 2005;16(12):3742-7.

16. Peer G, Kivity S, Agami O, Fireman E, Silverberg D, Blum M, et al. Randomised crossover trial of naltrexone in uraemic pruritus. Lancet. 1996;348(9041):1552-4.

17. Gutstein H, Akil H. Chapter 23: Opioid analgesics. In: The pharmacologic basis of therapeutics. 10th ed. New York, NY: McGraw Hill; 2001. p. 599.

18. Nalbuphine $\mathrm{HCl}$ Injection Solution. Labelling Information, Hospira, Inc. Lake Forest, IL. October 2007.

19. Cohen SE, Ratner EF, Kreitzman TR, Archer JH, Mignano LR. Nalbuphine is better than naloxone for treatment of side effects after epidural morphine. Anesth Analg. 1992;75(5):747-52.

20. Liao CC, Chang CS, Tseng CH, Sheen MJ, Tsai SC, Chang YL, et al. Efficacy of intramuscular nalbuphine versus diphenhydramine for the prevention of epidural morphine-induced pruritus after cesarean delivery. Chang Gung Med J. 2011;34(2):172-8.

21. Wang JJ, Ho ST, Hu OY. Comparison of intravenous nalbuphine infusion versus saline as an adjuvant for epidural morphine. Reg Anesth. 1996;21(3):214-8.

22. Wang JJ, Ho ST, Tzeng Jl. Comparison of intravenous nalbuphine infusion versus naloxone in the prevention of epidural morphine-related side effects. Reg Anesth Pain Med. 1998;23(5):479-84.

23. Wittels B, Glosten B, Faure EA, Moawad AH, Ismail M, Hibbard J, et al. Opioid antagonist adjuncts to epidural morphine for postcesarean analgesia: maternal outcomes. Anesth Analg. 1993;77(5):925-32.

24. Hawi A, Hunter R, Morford L, Sciascia T. Nalbuphine attenuates itch in the Substance-P induced mouse model. Acta Derm Venereol. 2013;93:S634.
25. Johnson SJ. Opioid safety in patients with renal or hepatic dysfunction. In: Pain Treatment Topics. 2007. http://paincommunity.org/blog/wp-content/ uploads/Opioids-Renal-Hepatic-Dysfunction.pdf.

26. Mercadante S, Arcuri E. Opioids and renal function. J Pain. 2004;5(1):2-19.

27. Smith HS. Opioid metabolism. Mayo Clin Proc. 2009;84(7):613-24.

28. Aitkenhead AR, Lin ES, Achola KJ. The pharmacokinetics of oral and intravenous nalbuphine in healthy volunteers. Br J Clin Pharmacol. 1988;25(2):264-8.

29. Jaillon P, Gardin ME, Lecocq B, Richard MO, Meignan S, Blondel Y, et al. Pharmacokinetics of nalbuphine in infants, young healthy volunteers, and elderly patients. Clin Pharmacol Ther. 1989;46(2):226-33.

30. Errick JK, Heel RC. Nalbuphine. A preliminary review of its pharmacological properties and therapeutic efficacy. Drugs. 1983;26(3):191-211.

31. Schmidt WK, Tam SW, Shotzberger GS, Smith Jr DH, Clark R, Vernier VG. Nalbuphine. Drug Alcohol Depend. 1985;14(3-4):339-62.

\section{Submit your next manuscript to BioMed Central and take full advantage of:}

- Convenient online submission

- Thorough peer review

- No space constraints or color figure charges

- Immediate publication on acceptance

- Inclusion in PubMed, CAS, Scopus and Google Scholar

- Research which is freely available for redistribution

Submit your manuscript at www.biomedcentral.com/submit 